\title{
Three-dimensional Modelling of Coal Combustion in Blast Furnace
}

\author{
Yansong SHEN, ${ }^{1)}$ Baoyu GUO, ${ }^{1)}$ Aibing YU, ${ }^{1)}$ Daniel MALDONADO, ${ }^{2)}$ Peter AUSTIN ${ }^{21}$ and Paul ZULLI ${ }^{2)}$ \\ 1) Lab for Simulation and Modelling of Particulate Systems, School of Materials Science and Engineering, University of New \\ South Wales, Sydney, NSW 2052, Australia. $\quad$ 2) BlueScope Steel Research, P.O. Box 202, Port Kembla, NSW 2505, \\ Australia.
}

(Received on December 18, 2007; accepted on March 31, 2008)

\begin{abstract}
Pulverized coal injection technology is widely used in blast furnace ironmaking due to economic, operational and environmental benefits. High burnout within the tuyere and raceway is required for high coal injection rate operation. In order to analyze the flow and combustion in the tuyere and raceway more accurately and reliably, a three-dimensional model of coal combustion is developed. This model is validated against the measurements from two pilot scale test rigs in terms of gas species composition and coal burnout. The gas-solid flow and coal combustion are simulated and analysed. The results indicate that compared to our previous model, the present model is able to provide more detailed gas species distributions and better describe the evolutions of coal particles. It is more sensitive to various parameters and hence more robust in examining various blast furnace operations.
\end{abstract}

KEY WORDS: coal combustion; blast furnace; pulverized coal injection; numerical simulation.

\section{Introduction}

Blast furnace plays a key role in ironmaking industry. In this process, pulverized coal is injected into the blast furnace raceway as a supplementary fuel to substitute expensive coke. This technology, often referred to as PCI (pulverized coal injection), has been recognised as a means of cost reduction, stable operation and coal supply flexibility. ${ }^{1,2)}$ Efforts to capitalise on the economic, operational and environmental benefits have led to high injection rates of pulverized coal worldwide, and currently injection of $180-200 \mathrm{~kg}$ coal per tonne of hot metal $(\mathrm{kg} / \mathrm{t}-\mathrm{HM})$ is not uncommon. Unfortunately, a higher coal injection rate results in a lower coal burnout (i.e., lower combustion efficiency). As a result, the temperature in the raceway will be decreased, and the unburnt char residue will deteriorate the permeability of the raceway boundary and probably other zones in the furnace. ${ }^{3,4)}$ Consequently, technologies to maximize coal burnout are of great significance for lowering operational costs and maintaining stable blast furnace operation. In this connection, a comprehensive understanding of the coal combustion process within the tuyere and raceway is indispensable for optimising coal selection and blast parameters.

It is difficult to access the raceway in a practical blast furnace due to the presence of molten metal, high pressure and temperature. In fact, to date few detailed measurements of coal combustion in the raceway have been reported. As an alternative approach, mathematical modelling provides a cost-effective tool for investigating the flow and combustion process. From a mathematical modelling perspective, the PCI process involves turbulent gas-solid two-phase flow coupled with momentum/mass/heat transfer and various homogenous and heterogeneous chemical reactions. A review of the history of PCI modelling in one-dimension and two-dimension can be found elsewhere. ${ }^{5)}$ In general, one-dimensional modelling was developed in the 1980s. ${ }^{6-8)}$ The turbulent feature in the raceway or the divergence of the jet exiting the tuyere was not considered. Two-dimensional (2D) models were developed in the 1990s to clarify the flow, heat transfer and reactions of coal in the tuyere and raceway. ${ }^{9-12)}$ However, a 2D model can only generate results qualitatively useful in practice. To overcome this limitation, three-dimensional (3D) models are needed. To date, a few 3D studies have been reported in the literature. ${ }^{13-17)}$ Murai et al. ${ }^{13)}$ and Goto et al. ${ }^{14)}$ reported a 3D simulation for blowpipe and on this basis some lance arrangements were examined for co-injections of coal/plastic and coal/gas. Du et al. ${ }^{15)}$ reported a model for blowpipe and tuyere. The raceway was not considered and the natural expansion of blast and coal plume after exiting tuyere was not predicted in both models. Nogami et al. ${ }^{16)}$ reported a model of PCI for raceway considering coke particle movement using discrete element method. This approach is interesting but difficult to be applied generally to a practical system where the number of particles is huge. Guo et al. ${ }^{17)}$ recently reported a model for tuyere and raceway cavity, and demonstrated that the model can describe some typical phenomena of coal combustion. However, this model showed a limited capability, e.g. in predicting gas composition, especially $\mathrm{CO}$ concentration, which is important under blast furnace PCI conditions. Another deficiency is that the model 
reported an insufficient sensitivity to the changes in some operational parameters widely used in the commercial blast furnaces, compared with that in the measurement.

To overcome these problems, a 3D numerical model is further developed in the present study for simulating the coal combustion in the tuyere and raceway cavity. Compared with the previous model, the present model is improved by several modifications. In particular, it considers two additional gasification reactions, so that it can predict not only the burnout but also gas composition. The model is validated against the experimental data collected from a pilot-scale test rig in terms of both gas composition and coal burnout. Then the flow pattern for gas and particle phases, as well as the coal combustion characteristics are analysed in details for the 3D geometry in terms of burnout and gas composition.

\section{Model Formulation and Validation}

\subsection{Governing Equations for Flow}

The gaseous phase is described by the transport equations of the continuum phase. Three-dimensional, steadystate Reynolds averaged Navier-Stokes equations closed by a standard $k-\varepsilon$ turbulence model are solved for turbulent gas flow. The governing equations solved for the gas phase include mass, momentum, turbulence kinetic energy, turbulence dissipation rate, enthalpy and a number of species $\left(\mathrm{O}_{2}, \mathrm{CO}_{2}, \mathrm{CO}, \mathrm{H}_{2}, \mathrm{H}_{2} \mathrm{O}\right.$ and volatiles, as used by others. ${ }^{18,19)}$ For completeness, they are given below.

The continuity and momentum equations in tensor notation are

$$
\begin{array}{r}
\nabla \cdot(\rho \mathbf{U})=0 \ldots \ldots \ldots \ldots \ldots \ldots \ldots \ldots \ldots \ldots \ldots \ldots \ldots \\
\nabla \cdot(\rho \mathbf{U} \otimes \mathbf{U})-\nabla \cdot\left(\mu_{\mathrm{eff}}\left(\nabla \mathbf{U}+(\nabla \mathbf{U})^{T}\right)\right)=\mathbf{B}-\nabla p^{\prime}
\end{array}
$$

where $\rho$ and $\mathbf{U}$ are the mean density and velocity. $\mathbf{B}$ is the drag force by particle phase. $p^{\prime}$ is the modified pressure. $\mu_{\text {eff }}$ is the effective viscosity defined by

$$
\mu_{\mathrm{eff}}=\mu+\mu_{\mathrm{t}}
$$

where $\mu$ is the laminar viscosity, $\mu_{\mathrm{t}}$ is the turbulent viscosity.

A generic scalar equation has the form

$$
\nabla \cdot\left(\rho \mathbf{U} \Phi-\left(\Gamma+\frac{\mu_{\mathrm{t}}}{\sigma_{\Phi}}\right) \nabla \Phi\right)=S_{\Phi}
$$

Energy equation is

$$
\nabla \cdot\left(\rho \mathbf{U} H-\left(\frac{\lambda}{C_{\mathrm{p}}}+\frac{\mu_{\mathrm{t}}}{\sigma_{H}}\right) \nabla H\right)=S_{\mathrm{E}}
$$

where $\lambda$ is the thermal conductivity. $C_{\mathrm{p}}$ is a mass fraction weighted specific heat. $H$ is the mean enthalpy. $S_{\mathrm{E}}$ is the heat source from the particle phase and radiation.

The transport equations for the turbulent kinetic energy $k$ and turbulence dissipation rate $\varepsilon$ according to the $k-\varepsilon$ model are

$$
\begin{gathered}
\nabla \cdot\left(\rho \mathbf{U} k-\left(\mu+\frac{\mu_{\mathrm{t}}}{\sigma_{k}}\right) \nabla k\right)=P_{k}-\rho \varepsilon \ldots \ldots \ldots . . . \\
\nabla \cdot\left(\rho \mathbf{U} \varepsilon-\left(\mu+\frac{\mu_{\mathrm{t}}}{\sigma_{\varepsilon}}\right) \nabla \varepsilon\right)=\frac{\varepsilon}{k}\left(C_{1} P-C_{2} \rho \varepsilon\right) .
\end{gathered}
$$

where $P_{k}$ is the turbulence production due to viscous forces.

Coal particles are treated as a dispersed phase using the Lagrangian method. Particle behaviours are tracked along the discrete particle trajectories without considering interaction between particles. Two forces are included to calculate the particle movement, i.e., drag force and turbulent dispersion force. The drag coefficient, $C_{\mathrm{D}}$, is given by a modified Schiller and Naumann correlation to ensure the correct limiting behaviour, ${ }^{20)}$

$$
C_{\mathrm{D}}=\max \left(24\left(1+0.15 \mathrm{Re}^{0.687}\right) / \mathrm{Re}, 0.44\right)
$$

The force, responsible for turbulent dispersion of particles, is determined by the turbulent velocity, $v_{\mathrm{f}}^{\prime}$, eddy length, $l_{\mathrm{e}}$, and lifetime, $\tau_{\mathrm{e}}{ }^{21)}$

$$
\begin{gathered}
v_{\mathrm{f}}^{\prime}=\Gamma(2 k / 3)^{0.5} \\
l_{\mathrm{e}}=\frac{C_{\mu}^{0.75} k^{1.5}}{\varepsilon} \\
\tau_{\mathrm{e}}=l_{\mathrm{e}} /(2 k / 3)^{0.5}
\end{gathered}
$$

where variable $\Gamma$ is a normally distributed random number, and $C_{\mu}$ is a turbulence constant. Full coupling of mass, momentum and energy of particles with the gaseous phase are carried out.

\subsection{Coal Combustion Reactions}

In general, the coal combustion is considered as a fourstage process $^{5)}$ : 1) heating up, 2) devolatilization of raw coal into two products, volatile matter (VM) and char, 3) gaseous combustion of VM, and 4) the oxidation/gasification of the residual char in the turbulent gas phase. The reactions considered in this work are listed in Table 1. No break-up or coalescence of particles is considered.

\subsubsection{Devolatilization}

The different types of devolatilization models have been proposed using a range of reaction schemes and rate expressions, where a model proposed by Ubhayakar ${ }^{22)}$ is widely used to simulate the devolatilization process. A pair of reactions ( $\mathrm{R} 1, \mathrm{R} 2)$ with different rate parameters $\left(k_{1}, k_{2}\right)$ and volatile yields $\left(\alpha_{1}, \alpha_{2}\right)$, compete to pyrolyse the raw coal,

Table 1. Chemical reactions considered.

\begin{tabular}{|l|l|}
\hline \multicolumn{1}{|c|}{ Reactions } & \multicolumn{1}{c|}{ Description } \\
\hline raw coal $\rightarrow \mathrm{VM}+$ char & Devolatilization \\
\hline $\mathrm{VM}+\mathrm{O}_{2} \rightarrow \mathrm{CO}_{2}+\mathrm{H}_{2} \mathrm{O}$ & Gaseous combustion \\
\hline char $+\mathrm{O}_{2} \rightarrow \mathrm{CO}_{2}$ & Char oxidation \\
\hline char $+\mathrm{CO}_{2} \rightarrow 2 \mathrm{CO}$ & Char gasification (solution loss) \\
\hline char $+\mathrm{H}_{2} \mathrm{O} \rightarrow \mathrm{CO}+\mathrm{H}_{2}$ & Char gasification (water gas) \\
\hline
\end{tabular}


$\begin{array}{ll}\text { raw coal } \sum_{k_{2}}^{k_{1}} \alpha_{1} \alpha_{1} \mathrm{VM}_{1}+\left(1-\alpha_{1}\right) \mathrm{char}_{1} \quad\left(1-\alpha_{2}\right) \text { char }_{2} & (\mathrm{R} 1, \text { Low temperature }) \\ \text { (R2, High temperature })\end{array}$

The rate of volatiles production is given by

$$
\frac{d \mathrm{VM}}{d t}=\left(\alpha_{1} k_{1}+\alpha_{2} k_{2}\right) C_{0}
$$

where $C_{0}$ is the mass of the raw coal, with initial value equal to the ash-free mass of the particle. The rate constants $k_{1}$ and $k_{2}$ are in Arrhenius form

$$
k=A \exp \left(-E / T_{\mathrm{p}}\right)
$$

where the Arrhenius rate constant $A$ and activation energy $E$ are $3.7 \times 10^{5} \mathrm{~s}^{-1}$ and $18000 \mathrm{~K}$ for R1 and $1.46 \times 10^{13} \mathrm{~s}^{-1}$ and $30189 \mathrm{~K}^{10)}$ for R2 (Table 2). The volatile species $\mathrm{VM}_{1}$ and $\mathrm{VM}_{2}$ are simplified as the same pure substances, where the composition is determined by the proximate and ultimate analyses of the coals considered. Base on the Ubhayakar model, the yield $\alpha_{1}$ is assigned unanimously as the volatile content of coal based on the proximate analysis (dry and ash free, daf), and the enhanced yield $\alpha_{2}$ is usually treated as being related to $\alpha_{1}$ in various forms in the literature, as summarized in Fig. 1. In general, $Q$-factor is used to represent the enhancement of the volatiles yield. It is reported that the measurement of the $Q$-factor is affected strongly by the experimental conditions employed such as particle size, furnace temperature, heating rate, ambient gas and residence time etc. ${ }^{23-25)}$ Due to widely scattering data, no universal relationship between $\alpha_{1}$ and $\alpha_{2}$ has been

\begin{tabular}{|c|c|c|c|c|c|}
\hline & \multirow[b]{2}{*}{$\alpha$} & \multicolumn{2}{|c|}{$k$} & \multirow{2}{*}{ Source } \\
\hline & & & $A, s^{-1}$ & $\mathrm{~T}, \mathrm{~K}$ & \\
\hline \multirow{2}{*}{1} & R1 & $a_{1}$ & $1.34 \times 10^{5}$ & 8852 & \multirow{2}{*}{$\begin{array}{l}\text { Suzuki }{ }^{8)} \\
\text { Guo }^{9)}\end{array}$} \\
\hline & $\mathrm{R} 2$ & 0.8 & $1.46 \times 10^{13}$ & 30189 & \\
\hline \multirow{2}{*}{2} & R1 & $a_{1}$ & $3.7 \times 10^{5}$ & 8852 & \multirow{2}{*}{$\mathrm{Du}^{16)}$} \\
\hline & $\mathrm{R} 2$ & $1.5 a_{1}$ & $1.46 \times 10^{13}$ & 30189 & \\
\hline \multirow{2}{*}{3} & R1 & $a_{1}$ & $3.7 \times 10^{5}$ & 18000 & \multirow{2}{*}{$\begin{array}{l}\text { Haywood } \\
\text { Aoki }^{12)}\end{array}$} \\
\hline & $\mathrm{R} 2$ & $2 \alpha_{1}$ & $1.46 \times 10^{13}$ & 30200 & \\
\hline \multirow{2}{*}{4} & R1 & $a_{1}$ & $3.7 \times 10^{5}$ & 18000 & \multirow{2}{*}{ Guo $^{17)}$} \\
\hline & $\mathrm{R} 2$ & $0.14+1.6 a_{1}$ & $1.46 \times 10^{13}$ & 30189 & \\
\hline \multirow{2}{*}{5} & R1 & $\alpha_{1}$ & $3.7 \times 10^{5}$ & 18000 & \multirow{2}{*}{ Present } \\
\hline & $\mathrm{R} 2$ & $1.25 \alpha_{1}^{2}+0.92 \alpha_{1}$ & $1.46 \times 10^{13}$ & 30189 & \\
\hline
\end{tabular}

Table 2. Kinetics of devolatilization modelling.

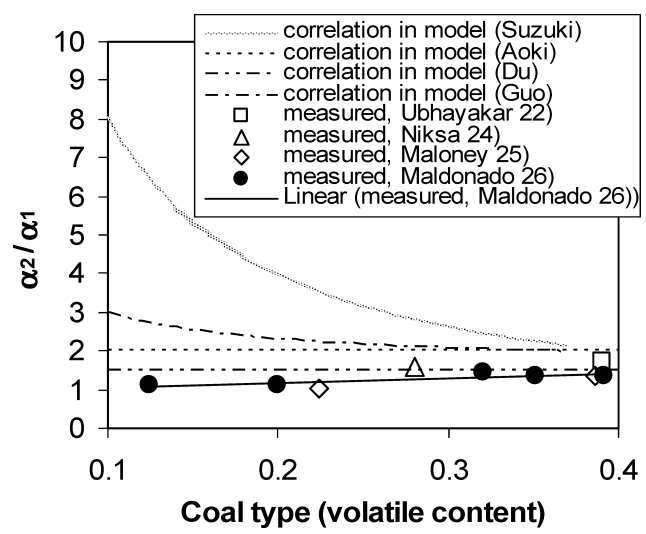

Fig. 1. Comparison of the relationships between $\alpha_{1}$ and $\alpha_{2}$ in the literature. achieved so far. After comparing the previous relationships with the coals considered in this study, it is found in Fig. 1 that the previous relationships (dash lines) do not fit the coals used well, particularly for low volatile coals. For this reason, a relationship is obtained by linearly fitting the measured $Q$-factors for a range of coals used in Australia. ${ }^{26)}$

\subsubsection{Gaseous Combustion and Other Species}

The volatiles, evolved as a fuel gas during the coal devolatilization, react with $\mathrm{O}_{2}$ to form $\mathrm{CO}_{2}$ and $\mathrm{H}_{2} \mathrm{O}$. This reaction is modelled by means of a single step reaction using the eddy dissipation model of Magnussen. ${ }^{27}$ The model assumes that the time scale of reaction is much shorter than that of turbulence and the gas-gas reaction is controlled by turbulent diffusion. The reaction rate, $R$, is proportional to the mixing time defined by the eddy properties, turbulent kinetic energy, $k$, and dissipation, $\varepsilon^{19)}$

$$
R=C_{\mathrm{A}} \frac{\varepsilon}{\kappa} \min \left(\frac{[\mathrm{I}]}{v_{\mathrm{I}}^{\prime}}\right)
$$

where [I] is the molar concentration of reactant components, $v_{\mathrm{I}}^{\prime}$ is the stoichiometric coefficient for $I$, and $\left.C_{\mathrm{A}}=4.0{ }^{19}\right)$

Concerning the gas composition, there are different approaches in the literature. Some investigators ${ }^{7,11,12)}$ estimated the gas composition using chemical equilibrium, with necessary heterogenous reactions considered, and others ${ }^{10,15,16)}$ did not report equilibrium and instead, considered more heterogeneous reactions. In the current model, the second approach is used, so the equilibrium among gas species is not included directly. More heterogenous reactions (Table 2 and Table 3 ) have been considered and the composition of gas species $\left(\mathrm{O}_{2}, \mathrm{CO}, \mathrm{CO}_{2}, \mathrm{H}_{2}, \mathrm{H}_{2} \mathrm{O}\right.$ and $\left.\mathrm{N}_{2}\right)$ is the consequence of these heterogeneous reactions at respective reaction rates. The rate constants also come from the published literature and are experiment-based. The main reasons for the present treatment are, i) the gas flow velocity is so high, and as a consequence, the residence time is too short to achieve full mixing and equilibrium in the test rig; ii) the gas composition measured in the test rig is indeed not in equilibrium. The gas compositions are obtained by solving transport equations for the mass fraction of each element.

\subsubsection{Char Oxidation and Gasification}

Another coal pyrolysis product, char, is assumed to be pure carbon. The Gibb model ${ }^{28)}$ is used for char oxidation, where the diffusion of oxygen within the pores of a char particle is considered, besides the external diffusion. By solving the oxygen diffusion equation analytically, the following equation is obtained for the rate of change in the char mass $m_{\mathrm{c}}$

Table 3. Kinetics of char gasification reactions.

\begin{tabular}{|l|c|c|}
\hline \multicolumn{1}{|c|}{ Reaction } & $\mathrm{A}_{\mathrm{c}}, \mathrm{m} \mathrm{s}^{-1} \mathrm{~K}^{-1}$ & $\mathrm{~T}_{\mathrm{c}}, \mathrm{K}$ \\
\hline $\mathrm{C}+\mathrm{CO}_{2}=2 \mathrm{CO}$ & 20230 & 39743 \\
\hline $\mathrm{C}+\mathrm{H}_{2} \mathrm{O}=\mathrm{CO}+\mathrm{H}_{2}$ & 606.9 & 32406 \\
\hline
\end{tabular}




$$
\frac{d m_{\mathrm{c}}}{d t}=-\frac{3 \phi}{1-e} \frac{M_{\mathrm{C}}}{M_{\mathrm{O}_{2}}} \frac{\rho_{\infty}}{\rho_{\mathrm{c}}}\left(k_{1}^{-1}+\left(k_{2}+k_{3}\right)^{-1}\right)^{-1} m_{\mathrm{c}}
$$

where the far field oxygen concentration $\rho_{\infty}$ is taken to be the time-averaged value obtained from the gas phase calculation, and $\rho_{\mathrm{c}}$ is the char density. The value of $\phi$ is assumed to depend on the particle temperature $T_{\mathrm{p}}$

$$
\frac{2(\phi-1)}{2-\phi}=A_{\mathrm{S}} \exp \left(-\frac{T_{\mathrm{S}}}{T_{\mathrm{p}}}\right)
$$

where the constants are $A_{\mathrm{S}}=0.0004$ and $T_{\mathrm{S}}=6240 \mathrm{~K} . k_{1}$ is the rate of external diffusion, $k_{2}$ is the surface reaction rate, and $k_{3}$ represents the rate of the internal diffusion and surface reaction. They are respectively given by

$$
\begin{aligned}
& k_{1}=\frac{D}{R_{\mathrm{p}}^{2}}, \quad k_{2}=(1-e) \frac{k_{\mathrm{c}}}{R_{\mathrm{p}}}, \\
& k_{3}=k_{\mathrm{c}} T_{\mathrm{p}}(\beta \operatorname{coth} \beta-1) / \beta^{2} a \\
& k_{\mathrm{c}}=A_{\mathrm{c}} T_{\mathrm{p}} \exp \left(-\frac{T_{\mathrm{c}}}{T_{\mathrm{p}}}\right), \quad \beta=R\left(\frac{k_{\mathrm{c}}}{D_{\mathrm{p}} e a}\right)^{0.5}
\end{aligned}
$$

The parameters include void fraction $(e)$, volume/internal surface area ratio $(\alpha)$ and particle radius $\left(R_{\mathrm{p}}\right) . D$ is the external diffusion coefficient of oxygen in the surrounding gas, and $k_{\mathrm{c}}$ is the carbon oxidation rate, defined by the modified Arrhenius equation. The values of the model constants are $A_{\mathrm{c}}=14 \mathrm{~m} / \mathrm{s}$ and $T_{\mathrm{c}}=21580 \mathrm{~K}^{28)}$

In the study of Guo et al., the gasification reactions of char were not considered so that the predicted gas composition was not sufficient. In comparison, two additional heterogeneous gas-char reactions are included here, namely, char gasification reactions with $\mathrm{CO}_{2}$ (solution loss reaction) and $\mathrm{H}_{2} \mathrm{O}$ (water gas reaction). The products of the two reactions are important for blast furnace practice. A model similar in form to the Gibb model for oxidation discussed above is employed to describe the $\mathrm{CO}_{2}$-char and $\mathrm{H}_{2} \mathrm{O}$-char gasification reactions. The reactions kinetics are based on a char gasification study for different Australian coals using a pressurised entrained flow reactor. ${ }^{29)}$ The values for the Arrhenius parameters are summarised in Table 3.

\subsection{Heat Transfer between Particle and Gas Phase}

The change of particle temperature is governed by three physical processes: convective heat transfer, latent heat transfer associated with mass transfer, and radiative heat transfer. The convective heat transfer $Q_{\mathrm{C}}$ is given by:

$$
Q_{\mathrm{C}}=\pi d \lambda \mathrm{Nu}\left(T_{\mathrm{g}}-T_{\mathrm{p}}\right)
$$

where $T_{\mathrm{g}}$ and $T_{\mathrm{p}}$ are the temperatures of the gas and of the particle, respectively, and $\mathrm{Nu}$ is the Nusselt number given by the Ranz-Marshall equation ${ }^{30)}$.

$$
\mathrm{Nu}=2+0.6 \operatorname{Re}^{0.5} \operatorname{Pr}^{0.33}
$$

The heat is distributed equally between the particle phase and gas phase. The heat transfer associated with mass trans- fer $Q_{\mathrm{M}}$ is given by:

$$
Q_{\mathrm{M}}=\sum \frac{d m_{\mathrm{p}}}{d t} H_{\text {reac }}
$$

where the sum is taken over all components of the particle for which heat transfer is taking place. $m_{\mathrm{p}}$ is the particle mass. $H_{\text {reac }}$ is the heat loss/gain by reactions, including the heat loss due to devolatilization of raw coal and two gasification reactions of char, and heat gain due to char oxidation reaction. The radiative heat transfer, $Q_{\mathrm{R}}$, for a particle with diameter $d_{\mathrm{p}}$, uniform temperature $T_{\mathrm{p}}$, and emissivity $\varepsilon_{\mathrm{p}}$, is given by:

$$
Q_{\mathrm{R}}=\varepsilon_{\mathrm{p}} A_{\mathrm{p}}\left(\pi I-\sigma T_{\mathrm{p}}^{4}\right)
$$

where $I$ is the radiation intensity on the particle surface area, $A_{\mathrm{p}}$, at the location of the particle. The radiation intensity $I$ is calculated using the discrete transfer model of Lockwood and Shah. ${ }^{31)} \sigma$ is the Stefan-Boltzmann constant. An equivalent amount of heat is removed from the radiation field. The value of the particle emissivity $\varepsilon_{\mathrm{p}}$ is expected to change as pyrolysis proceeds, i.e., it varies with the mass fractions of coal and char. A linear variation in $\varepsilon_{\mathrm{p}}$ is assumed from the raw coal value $\varepsilon_{\mathrm{p} \text { (coal) }}$ to the value for $\operatorname{char} \varepsilon_{\mathrm{p}(\mathrm{char})}$.

$$
\varepsilon_{\mathrm{p}}=\left(1-f_{\mathrm{v}}\right) \varepsilon_{\mathrm{p}(\mathrm{coal})}+f_{\mathrm{v}} \varepsilon_{\mathrm{p}(\mathrm{char})}
$$

where $f_{\mathrm{v}}$ is the fractional yield of volatiles. The value of $\varepsilon_{\mathrm{p}}$ is 1.0 for coal and 0.6 for char. ${ }^{32}$ )

Overall, the rate of change of temperature for the particle is then obtained from

$$
\sum\left(m_{\mathrm{p}} C_{\mathrm{p}}\right) \frac{d T_{\mathrm{p}}}{d t}=Q_{\mathrm{C}}+Q_{\mathrm{M}}+Q_{\mathrm{R}}
$$

where the sum in this equation is taken over all components of the particle. The model is solved based on the framework of ANSYS-CFX 10.0. Simulation conditions vary, as described below.

\subsection{Model Validity}

The model is validated systematically in terms of both burnout and gas composition, using the measurements from a pilot-scale test rig for two coals. The test rig is a combustion facility used in 1983-1985 in BHP Newcastle Laboratories, ${ }^{1)}$ which is schematically shown in Fig. 2.

Based on the above test rig, the solution domain is composed of a regular pipe combustor of $1.5 \mathrm{~m}$ long and $36 \mathrm{~mm}$ in radius, and a lance exit of $3 \mathrm{~mm}$ in radius, as shown in Fig. 3. The properties of the coals used in the test are summarized in Table 4.

The samples are taken along the centreline at the distances of $0.330,0.426,0.626$ and $1.030 \mathrm{~m}$ from the lance exit point, respectively.

The model is firstly validated in terms of gas composition. Figure 4 shows the measured and calculated gas mass fractions of $\mathrm{CO}, \mathrm{O}_{2}$, and $\mathrm{CO}_{2}$ along the centreline for Coal A. It can be seen that the major gas specie, i.e. $\mathrm{CO}_{2}$, agrees with the measured data. The trends for $\mathrm{CO}$ and $\mathrm{O}_{2}$ are qual- 


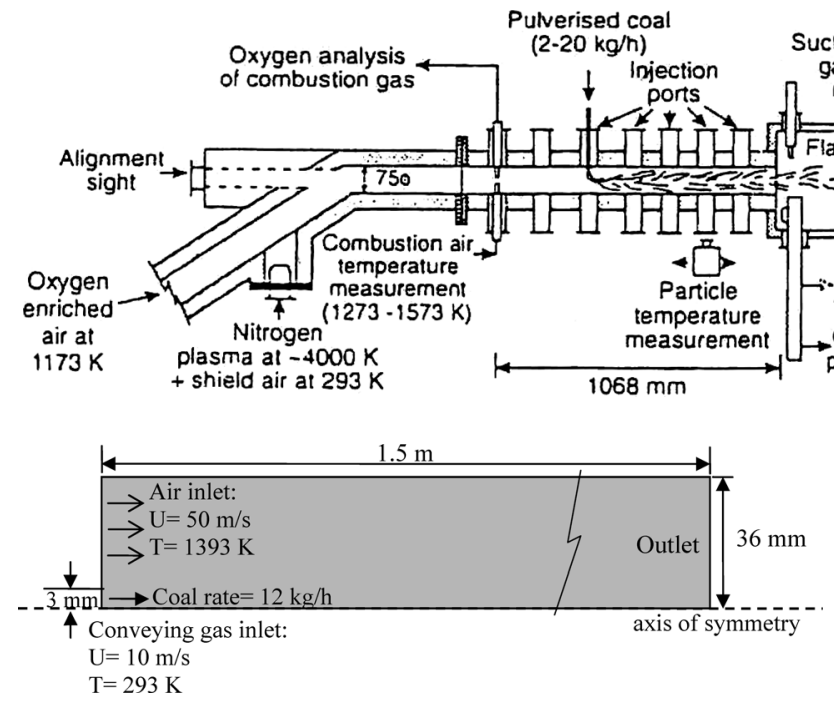

Fig. 3. Simulation condition of the validating test rig.

Table 4. Properties of the coals used in the experiment.

\begin{tabular}{|c|c|c|}
\hline & Coal A & Coal B \\
\hline VM, \% (daf) & 19.2 & 39.0 \\
\hline Ash, \% (ad) & 10.0 & 3.80 \\
\hline C, \% (daf) & 91.7 & 83.8 \\
\hline $\mathrm{H}, \%($ daf $)$ & 4.83 & 5.30 \\
\hline O, \% (daf) & 3.50 & 10.9 \\
\hline Mean size, $\mu \mathrm{m}$ & 40 & 40 \\
\hline
\end{tabular}

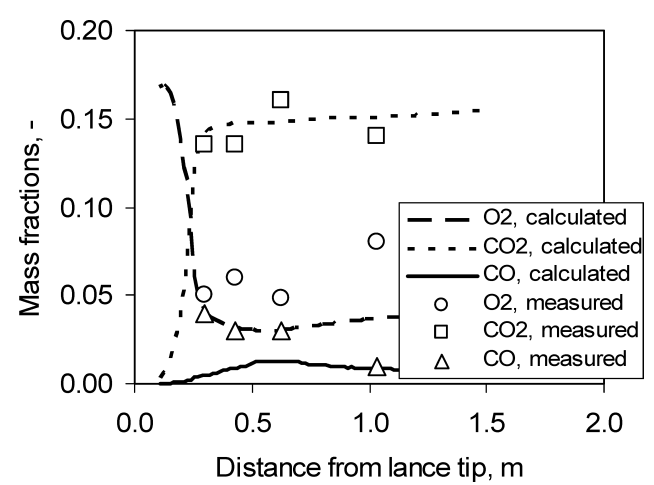

Fig. 4. Gas compositions of $\mathrm{CO}, \mathrm{O}_{2}$, and $\mathrm{CO}_{2}$ along the centreline.

itatively consistent with the measurements, while their values appear to be under-predicted. The likely reason for the difference is that VM (a mixture of $\mathrm{CO}, \mathrm{C}_{2} \mathrm{H}_{4}, \mathrm{C}_{3} \mathrm{H}_{8}, \mathrm{H}_{2}$ etc) is treated as a single pure substance, $\mathrm{C}_{x} \mathrm{H}_{y} \mathrm{O}_{z}$. Note that $\mathrm{H}_{2}$ was not reliably measured in the test rigs.

Moreover, the model is validated against the measured burnouts at four sampling positions along the centreline for Coal A and Coal B, respectively. The burnout is calculated according to the ash balance given below:

$$
\text { Burnout }=\left(1-\frac{m_{\mathrm{a}, 0}}{m_{\mathrm{a}}}\right) /\left(1-m_{\mathrm{a}, 0}\right)
$$

where $m_{\mathrm{a}, 0}$ is the ash content of the raw coal and $m_{\mathrm{a}}$ is the ash content of the residual. As defined, coal burnout represents the total weight loss of the organic fraction of the coal due to volatile release and char combustion/gasification reactions. Figure 5 compares the predicted burnout evolu-
Fig. 2. Schematic of the combustion facility used in 1983-1985 in BHP Newcastle Laboratories.

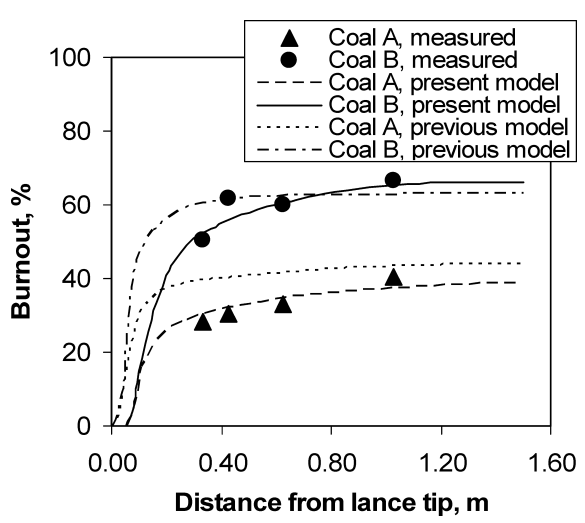

Fig. 5. Comparison of the predicted burnout evolutions with the measurements.

tions with the corresponding measurements. It shows that the burnout evolutions predicted by the present model agree well with the measured data for all the four sampling positions for two different coals.

\section{Model Application}

In this section, the model is applied to an experimental condition closer to a practical blast furnace, and a series of calculations are carried out to discuss the following aspects: 1) typical simulation results including flow pattern of gas and particle phases, distributions of gas species, and coal burnout; 2) comparisons with the previous model to identify the significance of model modifications.

\subsection{Simulation Conditions}

The test rig above is a coal combustor of simple geometry and the lance is only a simple tube without inclination. In order to generate more sensible information under the experimental conditions closer to a practical blast furnace, a more sophisticated test rig of pulverized coal combustion is used in BHP Newcastle Laboratories in 1998-2000, as shown in Fig. 6. ${ }^{1)}$ It provides an improved replication of the flow and thermo-chemical phenomena for pulverized coal injection process of blast furnace, since more detailed geometric characteristics of PCI operation are included, such as inclined co-axial lance (instead of a vertical tube) and diverging transition (instead of a regular pipe). Based on this rig geometry, the simulation domain and lance details are shown in Fig. 7.

Specifically, a two-layer coaxial lance is introduced into the tuyere at an inclination of 6 degree to the duct centreline with its tip on the centreline. Three separate gas streams (conveying gas for the coal, cooling gas for the lance and hot blast) are introduced into the domain (Fig. 


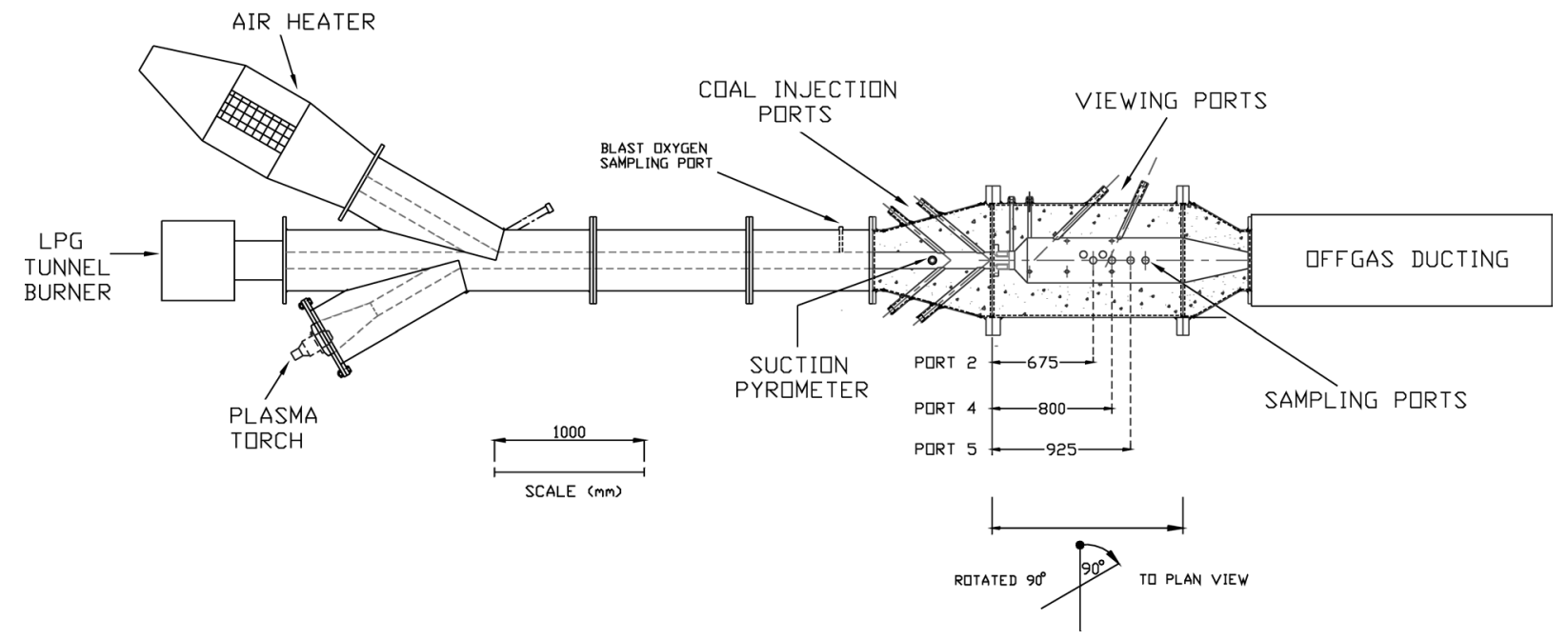

Fig. 6. Schematic of the pulverised coal combustion rig used in BHP Newcastle Laboratories in 1998-2000.

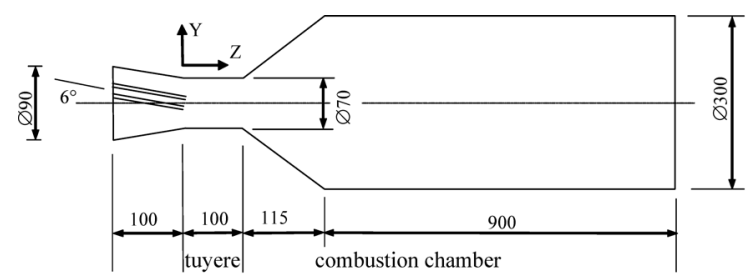

(a)

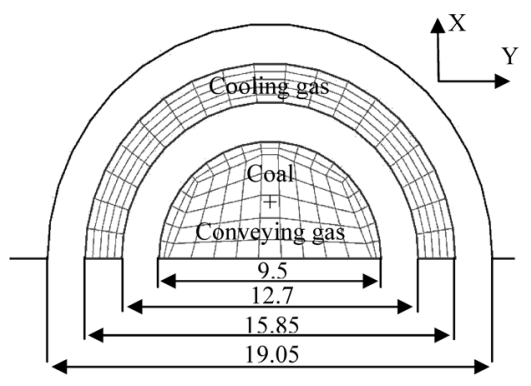

(b)

Fig. 7. Main dimensions (in $\mathrm{mm}$ ) of the model in a plan view (a) and lance details (b).

Table 5. Gas streams considered in the coal combustion model.

\begin{tabular}{|l|c|c|}
\hline & Flow rate & Temperature \\
\hline Blast $\left(20.9 \% \mathrm{O}_{2}\right)$ & $301 \mathrm{Nm}^{3} / \mathrm{h}$ & $1474 \mathrm{~K}$ \\
\hline Cooling gas $\left(20.9 \% \mathrm{O}_{2}\right)$ & $3.2 \mathrm{Nm}^{3} / \mathrm{h}$ & $600 \mathrm{~K}$ \\
\hline Conveying gas $\left(100 \% \mathrm{~N}_{2}\right)$ & $2.0 \mathrm{Nm}^{3} / \mathrm{h}$ & $323 \mathrm{~K}$ \\
\hline Coal & $25.5 \mathrm{~kg} / \mathrm{h}$ & $320 \mathrm{~K}$ \\
\hline
\end{tabular}

7(b)), with the flow rates and temperature summarized in Table 5. The computational mesh is a boundary-fitted, multi-block, structured finite volume mesh. No-slip flow and adiabatic heat transfer are applied to wall boundary conditions.

Three coals are used and their proximate and ultimate analyses are summarized in Tables 6 and 7, respectively. The particle sizes of the coals used are shown in Fig. 8 based on laser diffraction analysis. For each coal, 49 particle size classes are sampled in the range of 10-200 $\mu \mathrm{m}$.

\subsection{Typical Results}

Figure 9 shows the gas phase velocity vectors along the symmetry plane, and the coal (HC Fuel) particle trajectories coloured according to particle size. The results show
Table 6. Proximate analysis of the coals for general analysis.

\begin{tabular}{|l|c|c|c|}
\hline & Coal 1 & Coal 2* & Coal 3 \\
\hline Moisture, \% (ad) & 1.2 & 3.2 & 3.6 \\
\hline Volatile matter, \% (ad) & 19.95 & 32.5 & 35.1 \\
\hline Ash, \% (ad) & 9.7 & 9.8 & 6.2 \\
\hline Fixed carbon, \% (ad) & 69.1 & 54.5 & 55.1 \\
\hline Sulphur total, \% (ad) & 0.34 & 0.58 & 0.41 \\
\hline $\begin{array}{l}\text { Gross specific energy, } \\
\text { (ad) kJ/kg }\end{array}$ & 31.94 & 30.08 & 30.46 \\
\hline
\end{tabular}

Table 7. Ultimate analysis of the coals for general analysis.

\begin{tabular}{|c|c|c|c|}
\hline & Coal 1 & Coal 2 & Coal 3 \\
\hline $\mathrm{C}$ & 89.1 & 83.5 & 82.6 \\
\hline $\mathrm{H}$ & 4.7 & 5.3 & 5.44 \\
\hline $\mathrm{N}$ & 1.7 & 1.95 & 2.15 \\
\hline $\mathrm{S}$ & 0.37 & 0.6 & 0.3 \\
\hline O (by diff) & 4.1 & 8.6 & 9.5 \\
\hline
\end{tabular}

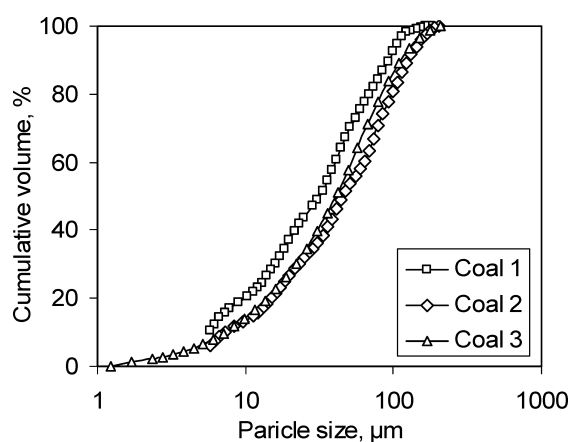

Fig. 8. Particle size distributions of the pulverized coals considered.

that the velocity of conveying gas at the lance tip is $\sim 9 \mathrm{~m} / \mathrm{s}$ and tuyere velocity is $\sim 120 \mathrm{~m} / \mathrm{s}$, which is consistent with the measured data. ${ }^{33)}$ After exiting the tuyere, the gas stream forms a high-speed, inclined central jet due to the inclined lance arrangement, and then the central jet expands in the radial direction and finally emerges near the exit of the chamber. A large-scale recirculation occurs near the wall in the main chamber. Similar to the gas field, particle trajectories form an inclined plume in the central region and a large scale recirculation of fine particles forms in the peripheral region near the wall. Along the central plume, it 


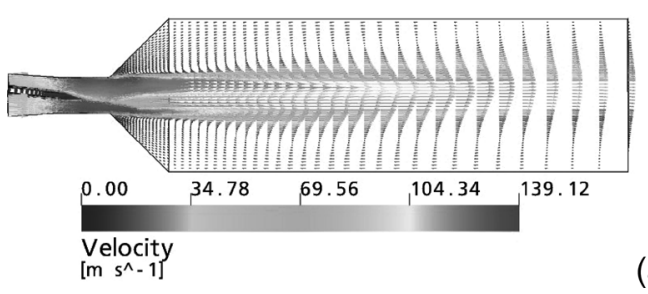

(a)

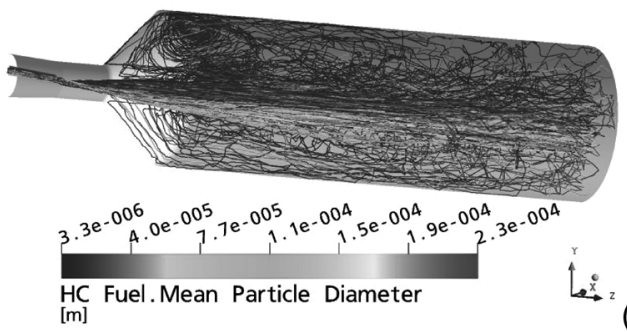

(b)

Fig. 9. Gas velocity vectors (a) and typical coal particle trajectories coloured according to particle size (b).

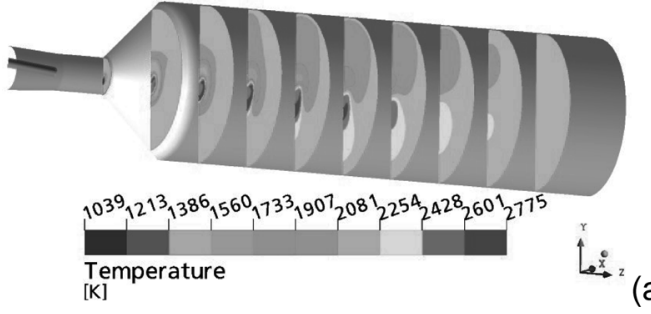

(a)
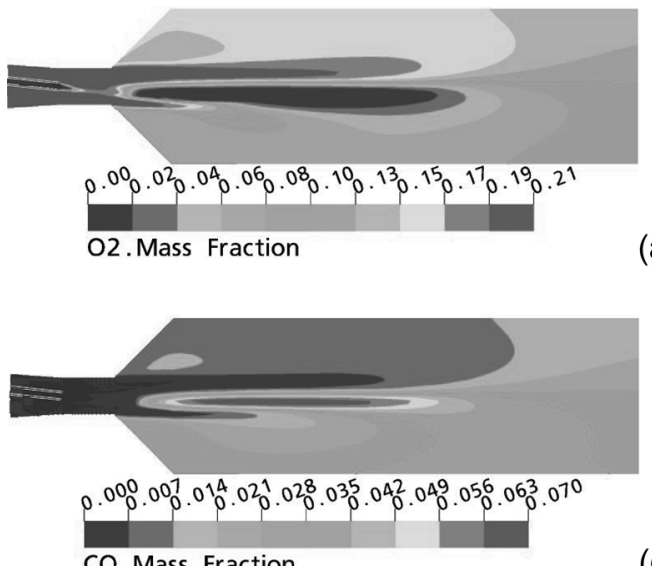

CO. Mass Fraction (a)

(c)

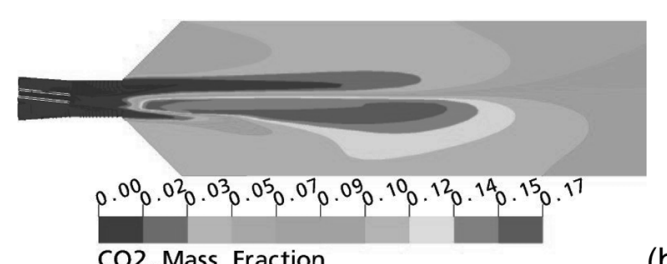

CO2.Mass Fraction

(b)

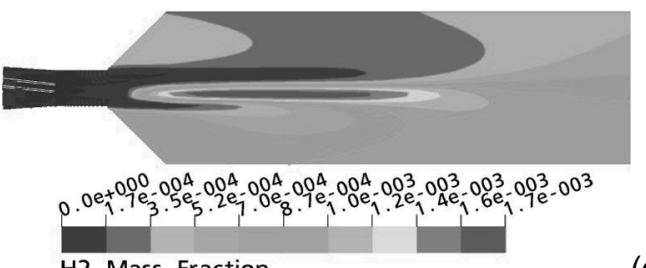

H2. Mass Fraction

(d)
Fig. 10. Gas phase temperature contours (a) and the (b)

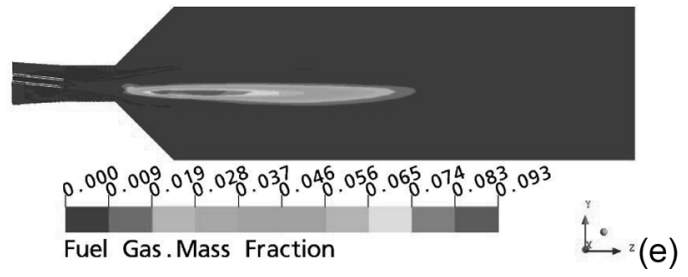

Fig. 11. Gas phase distributions: (a) $\mathrm{O}_{2}$, (b) $\mathrm{CO}_{2}$, (c) $\mathrm{CO}$, (d) $\mathrm{H}_{2}$, and (e) fuel gas (i.e. VM).

is found the mixing is very limited within the tuyere, but the plume tends to be more dispersed in the chamber.

Figure 10 shows the gas temperature distribution in a perspective view of slices (a) and the radiation intensity distribution along the symmetry plane (b). The results show an asymmetric temperature distribution, with a higher temperature in the lower part of the chamber resulting from the inclined lance arrangement. An annular zone of high temperature (flame front) forms in front of the tuyere at the surface of the coal plume, where the strong heat is released from rapid burning of volatiles due to direct access to the surrounding high oxygen concentration. The radiation intensity is much higher beyond the distance of $\sim 0.5 \mathrm{~m}$. This indicates that the heat feedback from downstream in both central and peripheral regions plays an important role in coal combustion simulation.

Figure 11 shows the distributions of $\mathrm{CO}, \mathrm{CO}_{2}, \mathrm{O}_{2}$, and $\mathrm{H}_{2}$. The stronger coal combustion at the lower part of the chamber leads to lower $\mathrm{O}_{2}$, higher $\mathrm{CO}, \mathrm{CO}_{2}$, and $\mathrm{H}_{2}$ mass fractions. It is noted that the inclusion of additional heterogenous reactions in this model, i.e. solution loss and water gas reactions, provides more complete and reliable predictions of gas species distributions compared with the previous study, in which the information of $\mathrm{CO}$ and $\mathrm{H}_{2}$ were not provided. Yet their concentrations are important when extending the modelling to the raceway. The volatile (fuel gas) starts to release after a preheating stage in front of the tuyere. This is comparable to the experimental observation by Ueno et $a l .{ }^{23)}$ The volatile content is high in the core of the coal plume. This is because a fuel-rich core exists surrounded by a high temperature reaction zone (Fig. 10 ), and a very high heating rate caused by the surrounding hot gas leads to a rapid production of volatile gases. On the other hand, in this oxygen-depleted/VM-rich zone, the over supply of volatiles is unlikely to be consumed completely through reacting with oxygen. As a result, the overall 

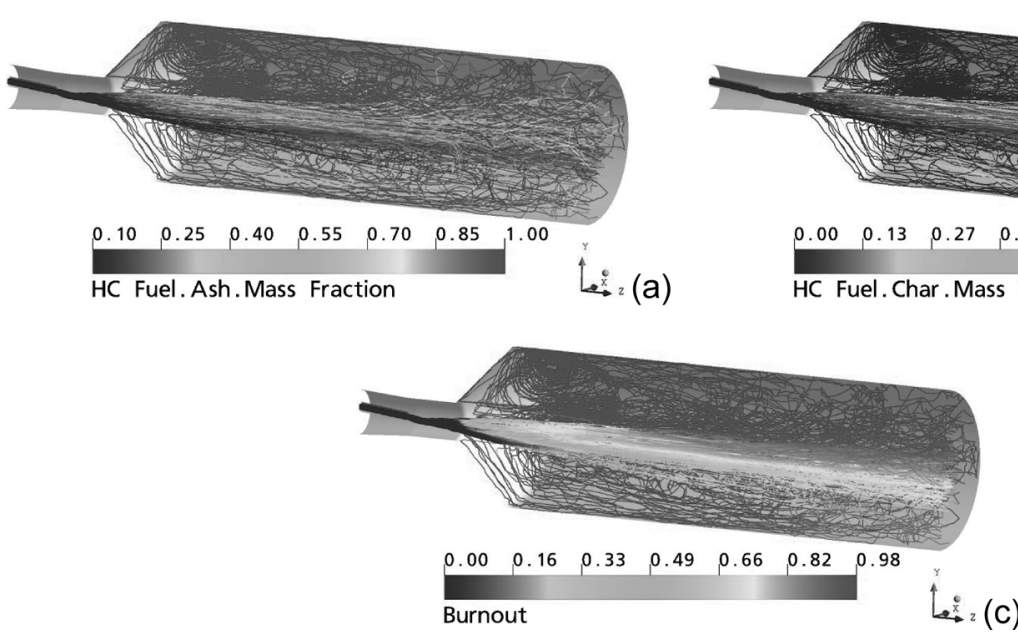

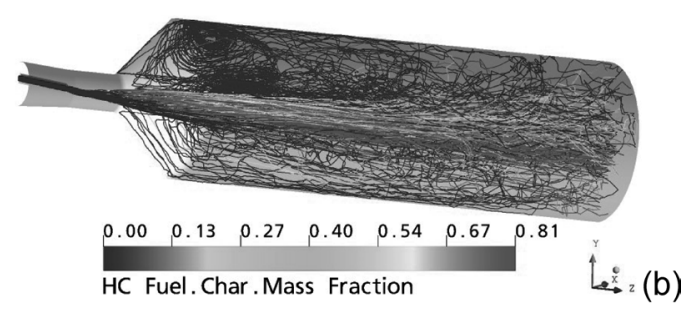

(b)
Fig. 12. Particle trajectories coloured by ash mass fraction (a), char mass fraction (b) and burnout (c).

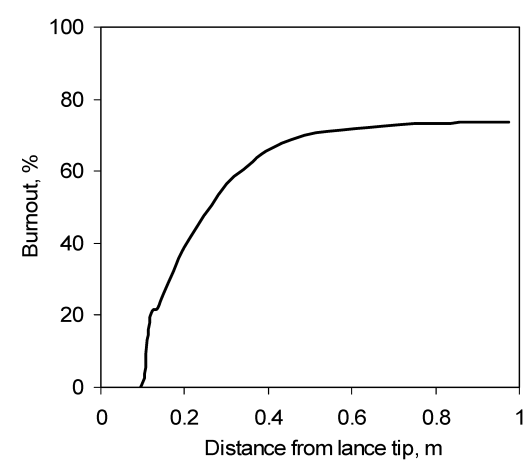

(a)

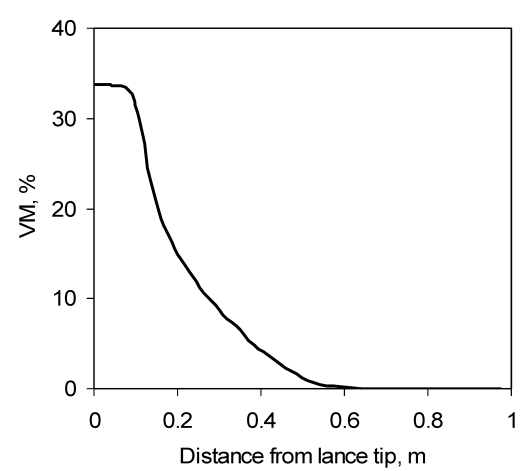

(b)
Fig. 13. Evolution of particle properties with distance from lance tip in terms of burnout (a) and volatile content (b) along the centreline. volatile builds up in the core of coal plume, while, beyond this zone, volatile matter is quickly consumed by the excess oxygen supply.

Coal burnout is evaluated in two directions, radial $(\mathrm{X}-\mathrm{Y})$ and axial $(\mathrm{Z})$. Concerning the radial direction $(\mathrm{X}-\mathrm{Y})$, Fig. 12 shows the particle trajectories coloured by ash mass fraction (a), char mass fraction (b), and burnout (c). It is found that: along the central coal plume, the upper part of the central plume has a relatively higher temperature, higher ash mass fraction, lower char mass fraction, and higher burnout, than the lower part. In comparison to particle trajectories coloured by particle size (Fig. 9(b)), the burning characteristics of these particle are consistent with the higher concentrations of fine particles along the upper part of the central plume. Additionally, compared to the gas species concentration contours (Fig. 11), the above burning profiles also depend on the availability of oxygen in the gas phase. The recirculating particles in the peripheral region show higher ash mass fractions, lower char mass fractions, and higher burnouts, compared with the central coal plume. A comparison among Figs. 11(a), 11(e), and 12(b) shows that, along the upstream central plume, volatile combustion is the primary reaction, as discussed above; conversely, at the peripheral region, the primary reactions of coal are char combustion and gasification, where finer particles of longer residence time are nearly burned off, leading to lower char mass fractions and then lower $\mathrm{CO}$ and $\mathrm{H}_{2}$ in this system, compared with the central plume.

In the axial direction $(Z)$, details of the coal combustion characteristics, including burnout and volatile content, are investigated along a centreline. Figure 13 shows the evolution of particles with the distance from lance tip in terms of burnout and volatile content. It shows that: burnout is very low before $0.06 \mathrm{~m}$, instead of commencing almost immediately after exiting the lance tip. Beyond $0.06 \mathrm{~m}$, the burnout evolution curve can be divided into two parts: 1) the upstream part covering the tuyere and the expansion section $(0.06-0.6 \mathrm{~m})$, where the burnout increases rapidly; and 2) the downstream part covering the rest of combustion chamber $(0.6-0.975 \mathrm{~m})$, where the burnout levels off at around $75 \%$. The two parts are connected via a relatively smooth transition at around $0.6 \mathrm{~m}$. Volatile content is relatively constant at around $32 \%$ up to $0.06 \mathrm{~m}$ and then decreases rapidly at the distance from 0.06 to $0.6 \mathrm{~m}$.

The comparison of burnout and VM curves in Fig. 13 indicates that, the burnout profile can be explained as follows. After a preheating stage, raw coal particles begin to release volatiles at $\sim 0.06 \mathrm{~m}$, that is, devolatilization commences at $\sim 0.06 \mathrm{~m}$. As a result of fast volatile release and combustion at the distance of $0.06-0.6 \mathrm{~m}$, particles are heated up rapidly and the burnout increases quickly to $\sim 75 \%$. Beyond $0.6 \mathrm{~m}$, volatiles are nearly burnt off, and slow char oxidation begins to dominate the process. Therefore, it can be concluded that the burnout level of coal along the central plume is determined by a combined contributions from volatile release/combustion upstream and char oxidation/ gasification downstream. The contribution of volatile release/combustion is more significant for raising the coal burnout level than the reactions of char. That is, the devolatilization is the most significant process in determining 
the coal burnout.

\subsection{Comparison with the Previous Model}

In order to clarify the importance of the new model, in this section, the new simulation results are compared with those generated by the previous model. At the same time, the validity of the new model is identified by comparing the results generated by the two models with the measurements in two different test rigs (Figs. 2 and 6), respectively.

New simulation results are then compared with those by the previous models concerning the burnout along the entire centreline. Figure 14 compares the coal burnout evolutions for three cases:

- Case $1\left(-\bigcirc^{-}\right.$): using the previous model (noting that the char gasification reactions were not included);

- Case $2(-\boldsymbol{-})$ : using the present model; and

- Case $3(-\square)$ : using the present model, with char gasification reactions switched off;

Case 1 and Case 2 are compared for downstream and upstream, respectively. As for the downstream, the two models predict a similar burnout evolution beyond $\sim 0.6 \mathrm{~m}$ for the base condition. Figure 15 shows more comparisons with the measurements, at a specific position downstream (925 mm from lance tip) under a wide-range of $\mathrm{O} / \mathrm{C}$ ratio (atomic O-to-C) from 1.85-3.97 (Table 8). The results indicate that, the final burnouts at that position predicted using the present and previous models appear similar, and they are both comparable to the measured data ${ }^{17,33)}$ at $925 \mathrm{~mm}-$ a sampling point far away from the lance tip. That is, the two model are both correct for the burnout prediction at this point, in spite of omitted char gasification reactions in the previous models.

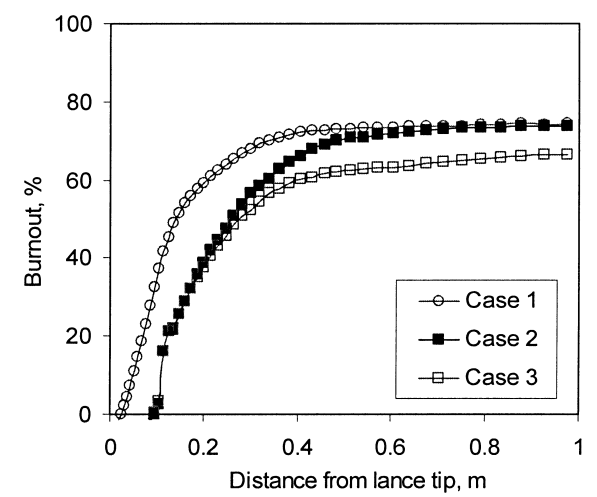

Fig. 14. Comparison of burnout evolutions predicted by the previous $(\bigcirc)$ model and present model ( $\mathbf{\square}$, with char gasification reactions; $\square$, without char gasification reactions).
However, comparison at a single point as used in Fig. 15 is not representative enough; it is necessary to examine the evolution along the test rig. Then we have Fig. 14 and Fig. 16, showing the two models predict different evolutions in terms of burnout, VM, and particle temperature. Specifically, at the upstream, the curves of Case 1 and Case 2 are significantly different (Fig. 14). Case 1 predicted an earlier and faster increase than Case 2, i.e., the preheating stage appeared to be missing somewhat. This is because, Case 1 predicted an earlier devolatilization and faster decrease in volatile content, and a much faster increase in particle temperature, from $\sim 320 \mathrm{~K}$ to $\sim 800 \mathrm{~K}$ within a very short distance from the lance tip (Fig. 16). As a result, all reactions depending on oxygen diffusion could be overwhelmed by this too strong devolatilization, which is believed to reduce the sensitivity of the model to some variables change, such as oxygen enrichment etc. Therefore, the present model is expected to provide more sensitive results to the change of various operating conditions, such as blast conditions and lance design. On the other hand, in order to clarify the effect of additional char gasification reactions on the burnout level, the evolutions of Case 2 and Case 3 are compared. It is found that the burnout curves are similar upstream but

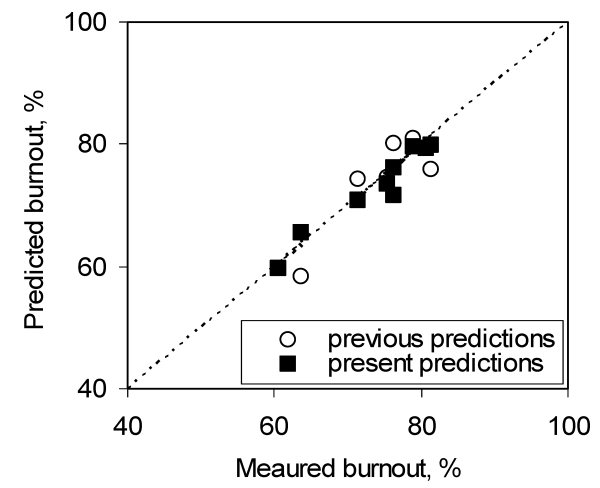

Fig. 15. Predicted $v s$. measured burnouts at $925 \mathrm{~mm}$ under various conditions for different coals.

Table 8. Conditions for the model validation.

\begin{tabular}{|c|c|c|c|}
\hline Coal & $\begin{array}{c}\text { Coal rate, } \\
\mathrm{kg} / \mathrm{h}\end{array}$ & $\begin{array}{c}\mathrm{O}_{2} \text { in blast, } \\
\%\end{array}$ & O/C ratio \\
\hline Coal 1 & 25.2 & 20.9 & 3.26 \\
\hline Coal 1 & 52.3 & 25.9 & 1.90 \\
\hline Coal 2 & 25.5 & 20.9 & 3.42 \\
\hline Coal 2 & 40.0 & 20.9 & 2.08 \\
\hline Coal 2 & 46.7 & 20.9 & 1.85 \\
\hline Coal 2 & 43.9 & 25.9 & 2.35 \\
\hline Coal 3 & 23.5 & 20.9 & 3.97 \\
\hline Coal 3 & 35.1 & 20.9 & 2.66 \\
\hline Coal 3 & 45.9 & 25.9 & 2.43 \\
\hline
\end{tabular}

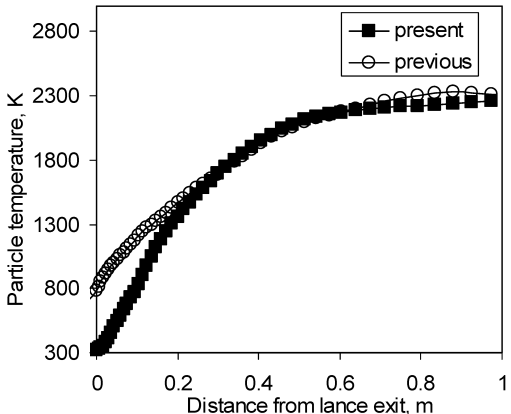

(b)
Fig. 16. Evolutions of volatiles contents (a) and particle temperatures (b), predicted by the present and previous models along the centreline. 
quite different downstream, where the downstream burnout level is increased from $\sim 65$ to $\sim 75 \%$. Since the downstream is controlled by char reactions as discussed above, the inclusion of two additional gasification reactions (i.e., solution loss and water gas) makes a significant difference to downstream burnout.

In order to find which model is more accurate, both models have been applied to the test rig (Fig. 2) where the evolutions were measured along the centreline both downstream and upstream. This gives Fig. 5 (in Sec. 2.4), which clearly demonstrates the present model is better. Moreover, it should be stressed that the char gasification reactions were not considered, and consequently insufficient validation was provided for gas composition in the previous study. The present model includes additional char reactions, solution loss and water gas reactions, which are important for the future application to practical blast furnace conditions. The two reactions are found to affect burnout evolution downstream much (Fig. 14). The present model hence predicts more complete gas species than the previous model, and Fig. 4 confirms the validity in term of gas composition. Another aspect is that the present model is found to be more sensitive to the change of combustion conditions as observed in the experiments (Fig. 5). Although not fully demonstrated in this paper, high accuracy and sufficient sensitivity are useful for reliable parametric studies.

\section{Conclusions}

A three-dimensional steady-state model of pulverised coal injection in the blast furnace has been developed to simulate the transport phenomena of flow and combustion in the tuyere and raceway cavity. This model is validated comprehensively against measurements from two pilot scale rigs in terms of gas species composition and coal burnout, both upstream and downstream.

The results indicate that: 1) the central coal plume has lower ash mass fraction, higher char mass fraction, and lower burnout, compared with the peripheral region, where fine coal particles recirculate; 2) coal combustion is dominated by volatile release/combustion at the central plume upstream and by char oxidation/gasification at the central plume downstream and at the peripheral region; 3) the burnout level of coal along the central plume is determined by combined contributions from both devolatilization upstream and char oxidation/gasification downstream. In terms of increasing coal burnout, the contribution of volatile release/combustion is more significant than the reactions of char.

Compared to the previous model, ${ }^{17}$ ) the present model has a few advantages. First, it can predict not only the burnout at one specific position but also the evolution of burnout along the test rig both downstream and upstream. Secondly, it can produce such evolutions for major gas species. Finally, the present model is found to be more sensitive to the change of combustion conditions such as blast temperature, oxygen enrichment, volatile content of coal etc. Consequently, it is more reliable and accurate in assessing the performance of coal under different PCI conditions.

\section{Acknowledgement}

The financial support of this project from BlueScope Steel and Australia Research Council is greatly acknowledged. Y. S. Shen wishes to thank the Univ. of NSW for providing the Endeavour International Postgraduate Research Scholarship for his $\mathrm{PhD}$ study.

\section{REFERENCES}

1) J. G. Mathieson, J. S. Truelove and H. Rogers: Fuel, 84 (2005), 1229.

2) W. P. Hutny, G. K. Lee and J. T. Price: Prog. Energy Combust Sci,, 17 (1991), 373.

3) J. M. Burgess: Prog. Energy Combust Sci., 11 (1985), 61.

4) Y. S. Shen, F. M. Shen, M. Zhu and Z. S. Zou: Proc. of Int. Blast Furnace Lower Zone Symp., AusIMM, Wollongong, (2002), 2.1.

5) K. Ishii: Advanced Pulverised Coal Injection Technology and Blast Furnace Operation, Elsevier Science Ltd., Oxford, (2000), 83.

6) J. C. He, M. Kuwabara and I. Muchi: Tetsu-to-Hagané, 72 (1986), 1847.

7) A. S. Jamaluddin, T. F. Wall and J. S. Truelove: Ironmaking Steelmaking, 13 (1986), 91.

8) T. Suzuki, L. D. Smoot, T. H. Fletcher and P. J. Smith: Combust. Sci. Technol., 45 (1986), 167.

9) Y. C. Guo, C. K. Chan and K. S. Lao: Fuel, 82 (2003), 893.

10) H. Aoki, H. Nogami, H. Tsuge, T. Miura and T. Furukawa: ISIJ Int., 33 (1993), 646.

11) K. Takeda and F. C. Lockwood: ISIJ Int., 37 (1997), 432.

12) R. J. Haywood, J. S. Truelove and M. J. McCarthy: Proc. of Ironmaking Conf. of AIME, ISS, Warrendale, PA, (1994), 437.

13) R. Murai, M. Sato and T. Ariyama: ISIJ Int., 44 (2004), 2168.

14) K. Goto, R. Murai, A. Murao, M. Sato, M. Asanuma and T. Ariyama: Proc. of Int. Blast Furnace Lower Zone Symp., AusIMM, Wollongong, (2002), 1.1.

15) S. W. Du and W. H. Chen: Int. Commun. Heat Mass Transfer, 33 (2006), 327.

16) H. Nogami, H. Yamaoka and K. Takatani: ISIJ Int., 44 (2004), 2150.

17) B. Y. Guo, P. Zulli, H. Roger, J. G. Mathieson and A. B. Yu: ISIJ Int., 45 (2005), 1272.

18) J. H. Ferziger: Computational Methods for Fluid Dynamics, Springer, New York, (2002).

19) ANSYS-CFX10.0 online help.

20) L. Schiller and A. Naumann: VDI Z., 77 (1933), 318.

21) A. D. Gosman and E. Ioannides: J. Energy, 7 (1983), 482.

22) S. K. Ubhayakar, D. B. Stickler, C. W. von Rosenberg, Jr. and R. E. Gannon: Proc. of 16th Int. Symp. on Combustion, The Combustion Institute, Pittsburgh, (1976), 427.

23) H. Ueno, K. Yamaguchi and K. Tamura: ISIJ Int., 33 (1993), 640.

24) S. Niksa, L. E. Keyd, W. B. Russel and D. A. Saville: Proc. of 20th Int. Symp. on Combustion, The Combustion Institute, Pittsburgh, (1984), 1445.

25) D. J. Maloney and R. G. Jenkins: Proc. of 20th Int. Symp. on Combustion, The Combustion Institute, Pittsburgh, (1984), 1435.

26) D. Maldonado, P. Zulli, Y. S. Shen, B. Y. Guo, A. B. Yu and H. Rogers: 5th Int. Conf. on Computational Fluid Dynamics in the Process Industries, CSIRO, Australia, (2006), (CD-ROM edition).

27) B. F. Magnussen and B. W. Hjertager: Proc. of 16th Int. Symp. on Combustion, The Combustion Institute, Pittsburgh, (1976), 719.

28) J. Gibb: Lecture at Course of Pulverised Coal Combustion, Imperial College, London, (1985).

29) S. S. Hla, D. J. Harries and D. G. Roberts: Proc. of Int. Conf. of Coal Science and Technology, ICSS\&T, Okinawa, (2005), (CD-ROM edition).

30) W. Ranz and W. Marshall: Chem. Eng. Prog., 48 (1952), 141.

31) F. C. Lockwood and N. G. Shah: Proc. of 18th Int. Symp. on Combustion, The Combustion Institute, Pittsburgh, (1981), 1405.

32) F. C. Lockwood, S. M. Rizvi and N. G. Shah: Proc. Inst. Mech. Eng., 200 (1986), 79.

33) H. Rogers: PCI Combustion Tests, Internal BlueScope Steel Report, (2004). 